\title{
Urban Households' Vulnerability to Multidimensional Poverty in Eastern Ethiopia
}

\author{
Amare Mabrie Yemata*
}

Economics Department, Haramaya University, P.O.box 138 Dira Dawa, Ethiopia

\section{A R T I C L E I N F O}

\section{Research Article}

Received 11 December 2017

Accepted 26 September 2018

Keywords:

Eastern Ethiopia

Households

Multidimensional poverty

Urban

Vulnerability

*Corresponding Author:

E-mail: amareecon@gmail.com \begin{abstract}
A B S T R A C T
Household level vulnerability analyses are becoming main issue in economics literature. Yet very few empirical works have been done to examine the extent of Eastern Ethiopia urban (Dira Dawa, Harar and Jigjiga towns) households' vulnerability to multidimensional poverty. This paper tried to fill the gap by using a survey that was conducted to collect information on household's characteristics, socioeconomic status, shocks experience and responses to shocks during the year 2016. Unlike conventional studies of household vulnerability, this study calculates household's probability of experiencing a broad and non-monetary characterization of poverty: the multidimensional poverty index using Structural Equation and Tobit model. The Structural Equation Model result revealed that, the health and education dimensions of multidimensional poverty significantly contributed a lot to households' vulnerability to multidimensional poverty. Based on the Tobit model result households' vulnerability to multidimensional poverty would be reduced if the household is wealthier, better educated healthier, employed and has the practice of reducing the size of meals at the time of shock. Contrary to this, if the household has large family size, prone to health problem, and has not developed the culture of reducing the number of meals per day, there is high risk of vulnerability to multidimensional poverty. Hence, the study recommended that there is a dire need for policies and programs that can improve wealth and education statuses of household members, create employment opportunity, promote family planning, improved health situation and accessibility of food for the vulnerable households.
\end{abstract}

DOI: https://doi.org/10.24925/turjaf.v6i11.1522-1529.1752

\section{Introduction}

Vulnerability is a situation in which an individual's exposure to being harmed or an unfavourable situation. This exposure can be studied in terms of the extent of risk or the shock faced or it may be studied in terms of the outcome or end result. Outcome based measures of vulnerability are forward-looking and aim at constructing distributions of outcomes in various states of the world. Under such an approach, the vulnerability measure is often an expected value of some measure of poverty. Chaudhuri et al. (2002) used cross section data and an error process model to estimate predicted consumption values and thus, infer vulnerability. Pritchett et al. (2000) define vulnerability as the probability that a house- hold will experience at least one episode of poverty in the near future and calculate a headcount rate to arrive at the proportion of households vulnerable to poverty. Using two panel data sets, they are able to arrive at a measure of vulnerability across gender and income groups over two periods. The above mentioned measures are outcome based in the sense that they view vulnerability through the lens of the out- come of vulnerability.
The sustainable livelihoods literature and food security literature adopt a different approach. They focus on the ownership of assets and social security in affecting vulnerability. Asset values are taken as proxies for vulnerabilities. The covariate risks attached with these assets are studied to fully understand their value in times of crisis. By their very nature, these indicators are highly contextual, require extensive survey information and hence, it is difficult to arrive at a generalized measure (Dercon, 2001).

Analyses of household level vulnerability to multidimensional poverty are becoming increasingly an important issue in economics literature. To reduce poverty policymakers need information on both the current incidence of poverty and also the magnitude of the peril of poverty, measured ex-ante (Calvo and Dercon, 2005). Such an outlook implicitly recognizes that poverty is a stochastic phenomenon. The current incidence of poverty is a critical indicator for the continuous reduction of wellbeing and it provides limited foresight into future poverty unless it is investigated deeply. Household's exposure to a variety of shocks and ability to effectively 
cope up with determined the likelihood to fall into poverty in the future.

Estimating vulnerability to multidimensional poverty, which indicates the probability of experiencing future poverty, is likely to reflect three critical advantages. Firstly, it produces poverty measures that are analogous to more established ones, including a headcount measure of vulnerability (Alwanget et al., 2001). Secondly, it sheds light on the relationship between vulnerable and poor households through identifying vulnerability that is the probability of being poor (Celidoni, 2013). Thirdly, it is applicable when only cross-sectional data are available. According to Hoddinott and Quisumbing (2003) the choice of appropriate approach for estimating vulnerability is a function of data availability on hand. Even though such analyses frequently done based on panel data with sufficient length and richness, but panel data set such a kind are rare in poor developing economies (Chaudhuri et al., 2002).

Few empirical works have been done to examine vulnerability of households in Eastern Ethiopian towns. This paper analysed vulnerability of households to multidimensional poverty using cross-sectional data about household characteristics, wealth, shock experiences and their responses. It estimates the ex-ante risk that households will, if currently non-poor, experience poverty one period ahead, or if currently poor, remains poor after a time.

Combining empirical cross sectional survey data that are manipulated through modelling techniques this data provides recent and detailed investigations on vulnerability of Eastern Ethiopia urban towns. It also makes a contribution to the vulnerability literature by estimating household's vulnerability to a broader measure of poverty; specifically multidimensional poverty, drawing on Alkire and Foster's (2011a) approach for calculating a Multidimensional Poverty Index (MPI). The use of MPI as a proxy for wellbeing, rather than more conventional monetary metrics like consumption, reflects the inherent limitation relying solely on monetary metrics of wellbeing. Furthermore, the study identifies those households that are likely to be poor in the near future, and in particular interest it could support to policymakers in designing social protection policies in the study area.

\section{Research Methodology}

\section{Description of the Study Area}

Dire Dawa is one of two chartered urban settlements in Ethiopia (the other being the capital city, Addis Ababa). Based on the 2007 census result of the Central Statistical Agency of Ethiopia (CSA, 2008), Dire Dawa has a total population of 342.827 of whom 171.930 were men and 170.897 women; 232.854 or $67.92 \%$ of the population were considered urban inhabitants. There were 75.693 households in Dire Dawa administrative council with an average of 4.5 persons per household.

Harari region, formerly known as region 13, is one of the nine National Regional States of Ethiopia, with the town of Harar as its capital. Based on the 2007 census result of the Central Statistical Agency of Ethiopia (CSA, 2008), Harari has a total population of 183.344, of whom
92.258 were men and 91.086 women; 99.321 or $54.17 \%$ of the population were urban inhabitants. For the entire region 46.169 households were counted, which results in an average for the Region of 3.9 persons to a household, with urban households having on average 3.4 and rural households 4.6 people.

Somali is one of the nine Regional States of Ethiopia covering the eastern-most part of the country, with Jijiga town as its capital. The Region borders with Kenya to the south-west, the Ethiopian regions of Oromia, Afar and Dire Dawa to the west, Djibouti to the north and Somalia to the north, east and south. Based on the 2007 Census result of the Central Statistical Agency of Ethiopia (CSA), the Somali Region had a total population of 4.439 .147 consisting of 2.468 .784 men and 1.970 .363 women; urban inhabitants' number 621.210 or $14 \%$ of the population. With an estimated area of $279.252 \mathrm{~km}^{2}$, the region had an estimated density of 15.9 people per square kilometre. For the entire region 665.397 households were counted, which results in an average for the Region of 6.6 persons to a household, with urban households having on average 6.3 and rural households 6.7 people.

\section{Sampling Technique and Data Collection}

To analyse household's vulnerability to multidimensional poverty, this study used primary data, which were collected in 2016 through interview schedule from 300 sample household heads from Dira Dawa, Harar and Jigjiga towns. The study used a two stage random sampling for selecting the ultimate sample units (households). In the first stage sample Kebeles were selected randomly from each town. Sample households were selected using a systematic random sampling technique in the second stage from each Kebele. Enumerators were trained on the content of the interview schedule and pre-test was conducted on few randomly selected households. Based on the pre-test input some modifications were made on the interview schedule. Individual interview with the sampled household heads was carried out by trained enumerators through the use of structured interview schedule.

\section{Method of Data Analysis}

Structural Equation Model (SEM): The study tried to examine effect of the three dimensions on multidimensional poverty index of households in the three towns of eastern Ethiopia. In constructing the structural equation model the core elements of the three dimensions of the index were considered as indicated in Figure 1.

Tobit model: In order to draw inferences about households' future vulnerability from multidimensional poverty through cross-sectional data Chaudhuri et al. (2002) make a number of simplifying assumptions in particular that cross-sectional variation in consumption is a good proxy for inter-temporal variance, if the economy structure remains stable. The level and variance of a household's wellbeing is considered to be a function of the stochastic nature of risk factors, and the extent to which households are exposed to them, as well as their capacity and desire to protect their wellbeing in the face of shocks. The following equation provides a reduced form of the household wellbeing. 


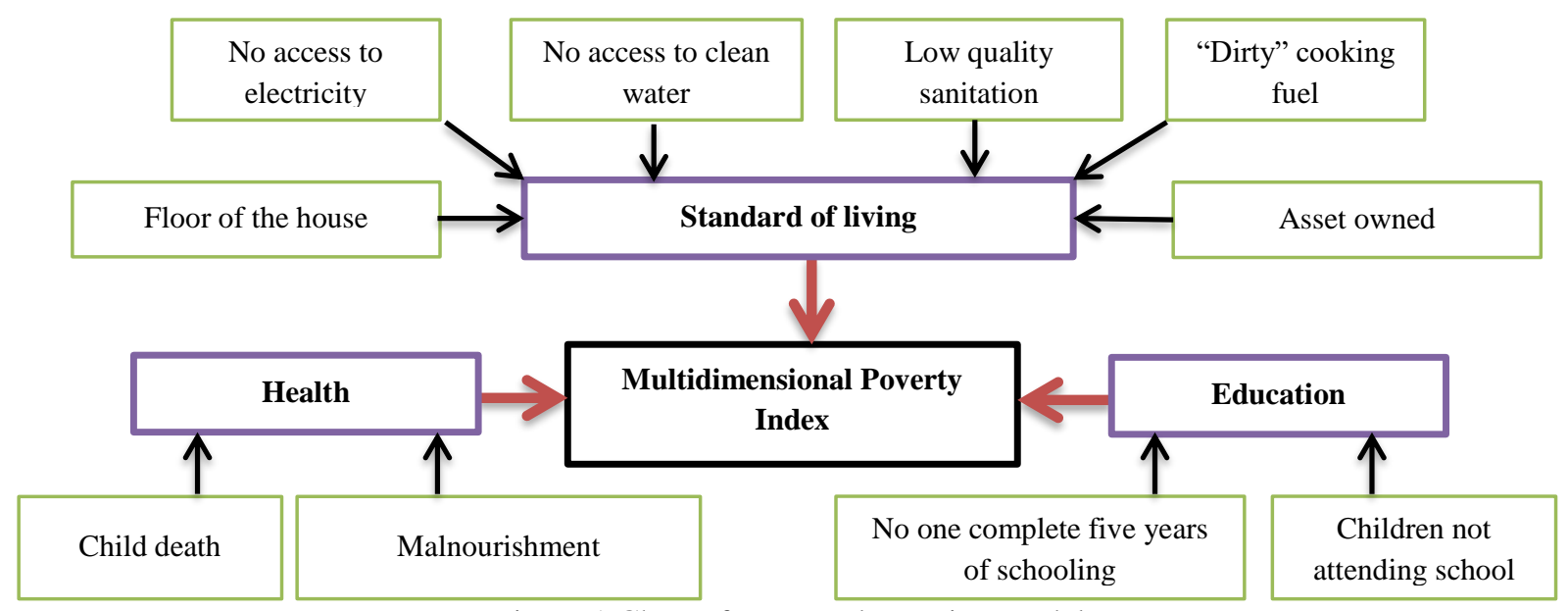

Figure 1 Chart of structural equation model

$$
\mathrm{W}_{\mathrm{it}}=\mathrm{f}\left(\mathrm{X}_{\mathrm{i}}, \mathrm{S}_{\mathrm{it}}, \mathrm{R}_{\mathrm{it}}, \mathrm{e}_{\mathrm{it}}\right)
$$

\section{Where:}

$\mathrm{W}_{\mathrm{i}}$ : Household $\mathrm{i}$ wellbeing at time $\mathrm{t}$.

$\mathrm{X}_{\mathrm{i}}$ : Is a vector of demographic characteristics and socio-economic status of household $\mathrm{i}$

$\mathrm{S}_{\mathrm{i}} \quad$ : Represents observed local shocks experienced by household i. Shocks include: loss of employment, income reduction, health and death and unexpected high price.

$\mathrm{R}_{\mathrm{i}} \quad$ : Refers strategies employed by household $\mathrm{i}$ in responses to the shocks. The parameter includes reduction of non-discretionary spending on education and demerit goods, relying on less expensive food, using traditional economy, selling asset, using financial resources (saving withdrawal, borrowing), reducing sizes and number of meals per day, and decreasing expenditures on cloths and other non-food items.

$\mathrm{e}_{\mathrm{it}} \quad$ : Is the error term that represents unobservable household level characteristics, idiosyncratic shocks and responses that contribute to difference in welfare outcomes.

Household wellbeing is the weighted deprivation score according to Alkire and Foster (2011a) method for calculating the MPI considering the three dimensions of wellbeing: health; education; and standard of living. This circumstance differs to most analyses of household vulnerability, which typically use per capita household expenditure, consumption, as welfare indicator. The vulnerability of a household $\mathrm{i}\left(\bar{V}_{i}\right)$ is the value of MPI (symbolised as $V_{i}$ ) greater than $\mathrm{Y}$ and less than $\mathrm{Z}$, which are the lower and upper limit of the index.

$$
\overline{\mathrm{V}}_{\mathrm{i}}=\operatorname{Pr}\left(\mathrm{Y}<\mathrm{V}_{\mathrm{i}}<\mathrm{Z}\right)
$$

The specification process that generates the stochastic wellbeing of a household $i$ is given as:

$$
\mathrm{V}_{\mathrm{i}}=\mathrm{X}_{\mathrm{i}} \beta+\mathrm{e}_{\mathrm{i}}
$$

$\mathrm{X}_{\mathrm{i}}$ : Represents a bundle of potential explanatory variables and $\beta$ is a vector of parameters to be estimated having a mean-zero disturbance term $\left(\mathrm{e}_{\mathrm{i}}\right)$,

$$
\mathrm{u}_{\mathrm{i}}=\mathrm{N}\left(0, \sigma^{2}\right) \text {. }
$$

The fitted value of Equation 3 is the expected level of wellbeing for household $i$. The variance of the disturbance term $\sigma^{2}$ is interpreted as the inter-temporal variance of wellbeing (Chaudhuri, 2003).

Let $\bar{V}_{i}$ denote the MPI that is incompletely observed in the regression since some of the households are nonvulnerable. For censoring from below, $\bar{V}_{i}$ is only observed if it exceeds a threshold level. For simplicity, let that threshold be zero, then we observe $\mathrm{V}_{\mathrm{i}}=\bar{V}_{i}$ if $\bar{V}_{i}>0$. Since negative values do not appear in the sample, the censoring mean exceeds the mean of $\bar{V}_{i}$. For censoring from below at zero, $\bar{V}_{i}$ is not completely observed when $\bar{V}_{i} \leq 0$, but it is known that $\bar{V}_{i}<0$ and for simplicity $\mathrm{V}_{\mathrm{i}}$ is then set to 0 . Since negative values are scaled up to zero, the censored mean also exceeds the mean of $\bar{V}_{i}$.

In order to determine the types of specification, nature of the dependent variable should be taken into account. The possible values of $\bar{V}_{i}$ ranges from 0 to 1 , which entails the possibly of two-sided censored data since vulnerability is based on range of values ( 0.33 to 0.51 of MPI). This circumstance could result in use two-sided censored Tobit Model.

$$
\mathrm{V}_{\mathrm{i}}=\left\{\begin{array}{l}
\mathrm{C}_{\mathrm{u}} \text { if } \overline{\mathrm{V}}_{\mathrm{i}} \geq \mathrm{C}_{\mathrm{u}} \\
\overline{\mathrm{V}}_{\mathrm{i}} \text { ifC }{ }_{\mathrm{l}}<\overline{\mathrm{V}}_{\mathrm{i}}<\mathrm{C}_{\mathrm{u}} \\
\mathrm{C}_{\mathrm{l}} \text { if } \overline{\mathrm{V}}_{\mathrm{i}} \leq \mathrm{C}_{1}
\end{array}\right.
$$

Thus, the mathematical representation could take the following format for the observed part of the dependent variable:

$$
\mathrm{V}_{\mathrm{i}}=\beta_{0}+\beta_{1} \mathrm{X}_{1 \mathrm{i}}+\beta_{2} \mathrm{X}_{2 \mathrm{i}}+\ldots+\beta_{\mathrm{n}} \mathrm{X}_{\mathrm{ni}}+\varepsilon_{\mathrm{i}}
$$

Where, $V_{i}$ and $X_{j i}$ are as defined above, $\beta_{i}$, is a matrix of the model parameters, and $\mu_{i}$ is the error term to capture the unexplained part of the model. All the basic assumptions of this method were thoroughly tested, and 
the necessary corrections made to generate robust analysis.

With luck, truncation and censoring might lead only to a shift up or down in the intercept, leaving slope coefficients unchanged; however, this is not the case (Cameron and. For example, if $\mathrm{E}\left[\mathrm{y}^{*} \mid \mathrm{X}\right]=\mathrm{X} \beta$ in the original model then truncation or censoring leads to $\mathrm{E}[\mathrm{y} \mid \mathrm{X}]$ being nonlinear in $\mathrm{x}$ and $\beta$ so that OLS gives inconsistent estimates of $\beta$ and hence inconsistent estimates of marginal effects. If the conditional distribution of $\mathrm{y}^{*}$ given repressors $\mathrm{x}$ is specified, then the parameters of this distribution can be consistently and efficiently estimated by ML estimation based on the conditional distribution of the censored or truncated $\mathrm{y}$. The Tobit model is a special case of a censored regression model, because the latent variable $\bar{V}_{i}$ cannot always be observed while the independent variable $\mathrm{X}_{\mathrm{i}}$ is observable.

This approach has also been used to estimate vulnerability to poverty across a range of different developing-country contexts, including: Papua New Guinea (Jha and Dang, 2010); Vietnam (Imai et al., 2011); rural China (Zhang and Wan, 2006); Guatemala (Tesiluc and Lindert, 2004); Nigeria (Chiwaula et al., 2011); Madagascar (Gunther and Harttgren, 2009); and Bangladesh (Azam and Imai, 2012); Vanuatu and the Solomon Islands (Lachlan, 2014).

\section{Result and Discussion}

\section{Descriptive Analysis}

This part of the analysis presents descriptive statistics on the demographic characteristics of the sampled households including family size, education and age of the head, dependency ratios and economic dependency, wealth index, shock suffered, and copping strategies employed. Since the core issue of this study is analysing household's vulnerability, many of the findings are disaggregated by vulnerability status.
Vulnerable households of the study area were significantly less educated, more elders and less wealthy as compared to the non-vulnerable ones (Table 1). However, the two groups of households have insignificant difference regarding sex of the head, family size, dependency ratio, being business men and employed.

Almost all vulnerable sampled household experienced an increase in real commodity prices, but it accounts $94 \%$ of non-vulnerable households. About $71 \%$ of vulnerable household experienced real income shock (job loss or reduced hours) while it is $64 \%$ for non-vulnerable ones. $53 \%$ and $30 \%$ of vulnerable sample households suffered death or serious illness of the household members but it is $35 \%$ and $28 \%$ for non-vulnerable households respectively.

Following the shock, more than three- fourth of both vulnerable and non-vulnerable sample households' reduced cloth and non-food expenses to cope up the shock. More than forty percent of both vulnerable and non-vulnerable households reduced number and size of meals following the shock. More number of vulnerable households' reduced consumption of demerit goods used less expenses good and used traditional activities (sought help from family /friend/neighbour) following the experience of shocks as compared to non-vulnerable households.

\section{Contributions of MPI Dimensions to the Overall Vulnerability}

As it can be observed from Table 2 more than half of the sampled households had poor sanitation (82.67\%), cooking fuel $(82.00 \%)$ and house quality $(61.67 \%)$. Nearly one-third $(36.33 \%)$ of them were malnourished, $39.67 \%$ did not have access to clean drinking water and $33.00 \%$ did not own at least two of the listed assets that enhance households' living standard. About $18 \%$ of the total sampled households faced child death prior to the survey year.

Table 1 Descriptive results of sample households by vulnerability status

\begin{tabular}{|c|c|c|c|}
\hline & Description & Vulnerable & Non-vulnerable \\
\hline \multirow{5}{*}{ Characteristics } & Family size & $4.28(0.22)$ & $4.09(0.13)$ \\
\hline & Dependency ratio & $0.82(0.06)$ & $0.81(0.04)$ \\
\hline & Education level of the head & $2.91(0.16) * * *$ & $3.55(0.14)$ \\
\hline & Age of the head & $47.44(1.53) * * *$ & $42.14(0.86)$ \\
\hline & Male head & $63 \%$ & $72 \%$ \\
\hline \multirow{3}{*}{ Wealth and income source } & Wealth index & $-0.06(0.26)^{*}$ & $-0.01(0.02)$ \\
\hline & Employed & $50 \%$ & $55 \%$ \\
\hline & Business man & $40 \%$ & $46 \%$ \\
\hline \multirow{4}{*}{ Observed shock experienced } & Real Income Shock & $71 \%$ & $64 \%$ \\
\hline & Labour Market shock & $53 \%$ & $35 \%$ \\
\hline & Health shock & $30 \%$ & $28 \%$ \\
\hline & Real inflation shock & $99 \%$ & $94 \%$ \\
\hline \multirow{9}{*}{ Observed copping strategy } & Reducing educational expense & $7 \%$ & $10 \%$ \\
\hline & Reducing demerit goods & $49 \%$ & $35 \%$ \\
\hline & Reducing number of meals & $48 \%$ & $43 \%$ \\
\hline & Reducing size of meals & $40 \%$ & $42 \%$ \\
\hline & Selling asset & $11 \%$ & $9 \%$ \\
\hline & Using financial resource & $22 \%$ & $26 \%$ \\
\hline & Using less expensive food & $42 \%$ & $34 \%$ \\
\hline & Reducing cloth and non-food expense & $80 \%$ & $76 \%$ \\
\hline & Traditional activities & $20 \%$ & $13 \%$ \\
\hline
\end{tabular}

*** and * respectively shows 1 and $10 \%$ level of significance, Values in parenthesis are standard errors. 
Table 2 Descriptive statistics of MPI indicators

\begin{tabular}{|c|c|c|}
\hline Dimension & Elements of each dimension & Percentage \\
\hline \multirow{2}{*}{ Health } & Child death five years prior to the survey & 17.67 \\
\hline & Malnourished member of the household & 36.33 \\
\hline \multirow{2}{*}{ Education } & No one complete five years of schooling & 9.00 \\
\hline & School-aged child (6-14 years) not attending school & 13.33 \\
\hline \multirow{6}{*}{$\begin{array}{l}\text { Standard } \\
\text { of living }\end{array}$} & No access to electricity & 17.00 \\
\hline & Have no access to clean drinking water & 39.67 \\
\hline & Low quality sanitation or shared toilet & 82.67 \\
\hline & "Dirty" cooking fuel (dung, firewood or charcoal) & 82.00 \\
\hline & Floor of the house is made of mud/dung & 61.67 \\
\hline & $\begin{array}{l}\text { Does not own more than two of radio, telephone, refrigerator, bicycle, motorcycle, car or } \\
\text { television }\end{array}$ & 33.00 \\
\hline
\end{tabular}

Table 3 Structural Equation Model (SEM) result

\begin{tabular}{|c|c|c|c|}
\hline Structure & Variable & Coefficient & Standard dev. \\
\hline \multirow{4}{*}{ Vulnerability } & Health & $0.483 * * *$ & 0.049 \\
\hline & Education & $0.231 * * *$ & 0.069 \\
\hline & Living standard & 0.203 & 0.136 \\
\hline & Constant & $-0.508^{*}$ & 0.275 \\
\hline \multirow{3}{*}{ Health } & Child death & $0.391 * * *$ & 0.028 \\
\hline & Malnourished member & $0.817 * * *$ & 0.022 \\
\hline & Constant & $-0.154 * * *$ & 0.039 \\
\hline \multirow{3}{*}{ Education } & Child out of school & $0.884 * * *$ & 0.019 \\
\hline & No one complete five years of schooling & $0.175 * * *$ & 0.022 \\
\hline & Constant & -0.052 & 0.017 \\
\hline \multirow{7}{*}{ Living standard } & Electric access & 0.012 & 0.022 \\
\hline & Sanitation type & $0.147 * * *$ & 0.022 \\
\hline & House floor & $0.054(* * *)$ & 0.018 \\
\hline & Dirty cooking fuel & $0.148 * * *$ & 0.023 \\
\hline & Access to clean water & 0.004 & 0.019 \\
\hline & Asset ownership & 0.010 & 0.020 \\
\hline & Constant & $1.342 * * *$ & 0.062 \\
\hline RMSEA & Root mean squared error of approximation & \multicolumn{2}{|c|}{0.092} \\
\hline CFI & Comparative fit index & \multicolumn{2}{|c|}{0.954} \\
\hline TLI & Tucker-Lewis index & \multicolumn{2}{|c|}{0.936} \\
\hline SRMR & Standardized root mean squared residual & \multicolumn{2}{|c|}{0.035} \\
\hline $\mathrm{CD}$ & Coefficient of determination & \multicolumn{2}{|c|}{0.995} \\
\hline
\end{tabular}

$* * *$ and $*$ respectively shows 1 and $10 \%$ level of significance

The Structural Equation Model (SEM) result in Table 3 shows that the three dimensions (health, education and living standard) have respective shares to explain the variation in the multidimensional poverty of sample households in Dire Dawa, Harar and Jigjiga town. The model result has acceptable output with coefficient of determination (CD) $99.50 \%$ and Root Mean Squared Error of Approximation (RMSEA) lower than 0.11, which is the threshold level. The CFI and TLI indices show the goodness of fit of the model as the value approaches to one. Since the stata result coefficients of those indices respectively are 0.95 and 0.94 , which indicates the models' goodness of fit is strong. Additionally, strength of the model can be also measured by the standardized root mean squared residual (SRMR), which is lower than 0.08 (Table 3).

The sample households were significantly vulnerability to multidimensional poverty from health and education dimensions. This indicates that multidimensional poverty of sample households in the study area significantly sourced from the two dimensions (health and education), while living standard has insignificant share.
Based on the model result suffering health and educational problems significantly aggravates households' poverty. Additionally, the two dimensions (child death and malnourishment) of health have significant effect in affecting health dimension of multidimensional poverty in the sample households of the three eastern Ethiopian towns. Similarly, the two elements of education (child dropout of school and no one complete five years of education) have significant effect on this dimension of multidimensional poverty. Three of the elements to measure living standard (sanitation, house floor and cooking fuel type) dimension of multidimensional poverty have significant effect on this dimension as to the model result (Table 3 ).

\section{Model Result and Discussion}

The two-sided censored tobit model result presented below shows that some of the covariates affect the dependent variable, multidimensional poverty index, significantly as expected priori. Some of the variables grouped under household characteristics affect the poverty level significantly as per the model result presented in Table 4 
As to the model result family size increment significantly increase vulnerability of the households in the study area. This finding is in line with other studies for instance Corbacho, et al. (2007) suggested that larger household size tended to be poorer in urban areas than in rural regions of Argentina. Successive increment in the family size may increase household's capacity to produce more and to have alternative income sources that ought to reduce the poverty level.

Better educated household heads have lower average levels of expected MPI deprivations compared to illiterate ones as to the model result in Table 4. Increasing household head's education level would significantly decrease households' weighted deprivation score. This result is consistent with studies that examined the link between education and vulnerability. It is also consistent with the findings of Jha and Dang (2010), which argued that households with more educated heads are less vulnerable to poverty. Furthermore, the study made by Lachlan (2011) stated that if the adult member of the household increases their secondary school by one year, then households' vulnerability would decrease by 0.08 values. This implies that lack of education is one of the factors that push households of the study area into vulnerability to multidimensional poverty.

Table 4 Determinants of vulnerability to multidimensional poverty

\begin{tabular}{|c|c|c|c|}
\hline & Description & Coefficient & Standard dev. \\
\hline \multirow{4}{*}{$\begin{array}{l}\text { Household } \\
\text { characteristics }\end{array}$} & Family size & $0.057 * *$ & 0.023 \\
\hline & Family size squared & $-0.005 * *$ & 0.002 \\
\hline & Dependency ratio & -0.029 & 0.025 \\
\hline & Sex of the head & -0.037 & 0.027 \\
\hline \multirow{4}{*}{ Head education } & Read and write & $-0.167 * * *$ & 0.039 \\
\hline & Elementary level & $-0.099 * * *$ & 0.038 \\
\hline & High school level & $-0.150 * * *$ & 0.043 \\
\hline & University and college & $-0.149 * * *$ & 0.038 \\
\hline \multirow{3}{*}{ Livelihood } & Wealth index & $-0.099 *$ & 0.054 \\
\hline & Business man & -0.034 & 0.026 \\
\hline & Employed & $-0.057 * *$ & 0.027 \\
\hline \multirow{4}{*}{$\begin{array}{l}\text { Observed shock } \\
\text { experienced }\end{array}$} & Real income shock & 0.025 & 0.029 \\
\hline & Labour market shock & 0.005 & 0.027 \\
\hline & Health shock & $0.061 * *$ & 0.026 \\
\hline & Real inflation shock & 0.115 & 0.077 \\
\hline \multirow{9}{*}{$\begin{array}{l}\text { Observed copping } \\
\text { strategy }\end{array}$} & Reducing educational expense & -0.065 & 0.042 \\
\hline & Reducing demerit goods & 0.017 & 0.025 \\
\hline & Reducing number of meals & $0.071 * * *$ & 0.027 \\
\hline & Reducing size of meals & $-0.058 * *$ & 0.027 \\
\hline & Selling asset & -0.035 & 0.040 \\
\hline & Using financial resource & -0.040 & 0.027 \\
\hline & Using less expensive food & -0.013 & 0.025 \\
\hline & Reducing cloth and non-food expense & 0.013 & 0.029 \\
\hline & Traditional activities & 0.047 & 0.031 \\
\hline Constant & & $0.216 * *$ & 0.088 \\
\hline $\mathrm{LR} \chi^{2}(24)$ & & 101.69 & \\
\hline Prob $>\chi^{2}$ & & 0.000 & \\
\hline Pseudo $\mathrm{R}^{2}$ & & 0.343 & \\
\hline
\end{tabular}

The household's wealth level and being employed in formal sectors significantly reduce vulnerability to poverty. Holding all covariates constant, households with a greater wealth index score tend to be less vulnerable owing to their lower rates of expected poverty. The negative sign indicates a reduction in deprivations or improvement in wellbeing if there is increment in household's wealth index. In fact, a one percent increases in household's wealth index decreases the vulnerability to its multidimensional poverty score by 0.099 for an average sample household in the study area. Additionally, if the household head is formally employed, then vulnerability to multidimensional poverty would significantly reduce household's future MPI deprivations because of having secured income source. This possibly demonstrates the importance of relatively stable and secured forms of income sources from formal employment than in other informal sources.

Households who experienced health shock such as death of the household head and other members and serious illness of any member strongly aggravates vulnerability of the household to multidimensional poverty. Outbreak of these unexpected shocks may distort the normal activities of the household that may in turn reduce the income or increase the expenditure. Thus, happening of those shocks would intend to increase vulnerability of the household to poverty in one or the other direction. The inclusion of observed shocks as well as responses to shocks stands household's endogenous capacity to smooth the effects of shocks on wellbeing (Kurosaki, 2010). 
Households that reduce size of meals per day tended to be less vulnerable; possibly suggesting that households, which practice this strategy would be able to smooth effects of unexpected shocks. However, reducing size of males is suboptimal as a coping mechanism in some contexts since it will reduce the necessary requirement of the family that is food (calorie intake). To the extent that reducing size of male during times of stress for less consideration than they might be worth otherwise, such reductions may, ultimately, weaken household's resilience to future shocks especially for health problems such as serious illness and death of the members of the family. On the other hand reducing the number of meals per day significantly aggravates the households' vulnerability to poverty in the study area.

\section{Conclusions and Recommendations}

This paper estimates the vulnerability of urban households in Eastern Ethiopia to experiencing multidimensional poverty. It combines unique empirical survey data with an approach to estimating vulnerability to poverty that is widely used in the development economics literature. It sharpens the analytical focus on household wellbeing, beyond current observed poverty, by identifying those households that are likely to experience multidimensional poverty in the future by examining households' demographic characteristics, socioeconomic status, exposure to shocks, as well as households' responses to shocks. Thus policymakers interested in social protection would therefore be well served by dedicating resources to forward-looking antipoverty policy interventions.

From the Structural Equation Model result, it is possible to conclude that death of child and malnourishment of the household member; child dropout of school and non-completion five years of education; sanitation, house floor and cooking fuel type have significant effect in affecting health, education and living standard dimension of multidimensional poverty in the sample households of the three eastern Ethiopian towns. To reduce the level of multidimensional poverty there is need of designing programs that can improve health, educational attainment and living situation of the society.

Households being wealthy, better educated and being employed in formal sectors of an economy reduces their vulnerability in the study area. This indicates the importance of accumulation of wealth, better education policies and the removal of barriers that prevent households from engaging in the formal sector of an economy. This implies that there is need of interventions by concerned parties on improvement of wealth creation, access to better education and employment opportunities in the formal sector of an economy.

Having large family size and exposure to health shock such as serious illness and death of the household member, increases household vulnerability to multidimensional poverty. Therefore there is need of strategies that can reduce family size such as motivating the poor society to use family planning and different medication facilities that can reduce death and serious illness of the society.
Reducing the size of meals as a strategy of coping mechanism reduces households' experience to future multidimensional poverty while reducing number of meals per day aggravates the vulnerability of the household for future multidimensional poverty. With this regard the government and other non-governmental organizations are expected to have remedies to increase the access of food for the poor society.

\section{References}

Alwang J, Paul B, Steen J. 2001. Vulnerability: A View from Different Disciplines. Social Protection, Washington: World Bank.

Azam M, Imai K. 2012. Households' Vulnerability to Idiosyncratic and Covariate Shocks - the case of Bangladeshll, Discussion Paper Serries DP2012-02, Kobe University Research Institute for Economics and Business Administration, Kobe Japan.

Calvo C, Dercon S. 2005. Measuring Individual Vulnerability. Discussion Paper Series Number 229, Oxford University Department of Economics.

CSA. 2008. Central Statistics Authority, Summary and statistical report of 2007 population and housing census. Addis Ababa, Ethiopia.

Chaudhuri S. 2003. Assessing Vulnerability to Poverty: Concepts Empirical methods and Illustrative Examples. mimeo. New York: Columbia University, Department of Economics.

Chaudhuri S, Jyotsna J, Asep S. 2002. Assessing Household Vulnerability to Poverty from Cross Sectional Data: A Methodology and Estimates from Indonesia. Discussion Paper no. 01022-52. New York: Columbia University.

Chiwaula LS, Witt R, Waibel H. 2011. An Asset-based Approach to Vulnerability: The Case of Small-scale Fishing Areas in Cameroon and Nigeria. The Journal of Development Studies 47 (2), pp.338-353.

Corbacho A, Mercedes Garcia-E, Gabriela L. 2007. Argentina: Macroeconomic Crisis and Household Vulnerability. Review of Development Economics 11 (1): pp.92-06.

Deon F, Lant HP. 2001. Estimating wealth effects without expenditure data - or tears: An application to educational enrolments in states of India. Demography, 38 (1): pp.115- 132.

Dercon S. 2001 Assessing Vulnerability to Poverty. Jesus College and CSAE, Oxford: University of Oxford, Department of Economics.

Gunther I, Kenneth H. 2009. Estimating Households Vulnerability to Idiosyncratic and Covariate Shocks: A Novel Method Applied in Madagascar. World Development 37: $1222-1234$.

Hoddinott J, Quisumbing A. 2003. Methods for microeconometric risk and vulnerability assessments: A review with empirical examples. Unpublished Manuscript.

Imai K, Gaiha R, Kang W. 2011. Vulnerability and Poverty Dynamics in Vietnam, Applied Economics, 43: 3603-3618.

Jha R, Dang T. 2010. Vulnerability to Poverty in Papua New Guinea in 1996. Asian Economic Journal 24(3): 235-251.

Kurosaki T. 2010. Targeting the Vulnerable and the Choice of Vulnerability Measures: Review and Application in Pakistan. The Pakistan Development Review, 49(2): 87-103.

Lachlan M. 2014. Households vulnerability to poverty Vanuatu and Solomon Island, Rmit University, Melborne, Australia

Luc C, Kalanidhi S. 2005. Towards an Understanding of Household Vulnerability in Rural Kenya. Journal of African Economies 14(4): 520-558.

Martina C. 2013. Vulnerability to poverty: an empirical comparison of alternative measures: Applied Economics 45(12): 1493-1506 
Pritchett L, Asep S, Sudarno S. 2000. Quantifying Vulnerability to Poverty: A Proposed Measure with Applications to Indonesia. SMERU Working Paper, Social Monitoring and Early Response Unit, Washington: World Bank.

Sabina A, James F. 2011a. Counting and Multidimensional Poverty Measurement. Journal of Public Economics 95: 476-487.

Sajeda A, Ashok S, Giorgio T. 2000. Does microcredit reach the poor and vulnerable? Evidence from northern Bangladesh. Unpublished Manuscript.
Tesliuc E, Lindert K. 2004 Risk and Vulnerability in Guatemala: A Quantitative and Qualitative Assessment. Social Protection Discussion Paper 0404. Washington: World Bank.

Zhang Y, Guanghua W. 2006. An Empirical Analysis of Household Vulnerability in Rural China. Journal of the Asia Pacific Economy, 11(2): 196-212. 